\title{
Review: some alcohol screening tests have acceptable test properties for use in general clinical populations of North American women
}

\author{
Bradley KA, Boyd-Wickizer J, Powell SH, et al. Alcohol screening questionnaires in women. A critical review.JAMA 1998 Jul \\ $8 ; 280: 166-71$.
}

\section{Question}

Are alcohol screening questionnaires sensitive and specific for identifying heavy drinking or alcohol abuse or dependence in women in general clinical populations in the US?

\section{Data sources}

English language studies were identified using Medline (1966 to July 1997) with a combination of the search terms alcoholism, alcohol drinking, screening, CAGE, BMAST, T-ACE, TACE, TWEAK, MAST, SMAST, SAAST, and AUDIT; Social Science and Science Citation Indexes; and bibliographies of relevant studies.

\section{Study selection}

Studies were selected if they compared a brief alcohol screening questionnaire ( $\leqslant 10$ items) with an appropriate criterion standard for alcohol abuse or dependence (ie, based on DSM-IV or ICD-10) or heavy drinking (ie, based on the Alcohol Use Disorder and Associated Disabilities Interview Schedule or a timeline follow back interview) in a generalisable clinical population of women in the US.

\section{Data extraction}

Sensitivity, specificity, and area under receiver operating characteristic (ROC) curve.

\section{Main results}

13 of 759 studies met the inclusion criteria. They evaluated 8 screening questionnaires in various settings (emergency department, primary care, and obstetric clinic), in different populations (black, white, and Hispanic), and assessed test properties using various cutoff points. Data were not meta-analysed because of study heterogeneity. The table lists test properties for 7 tests. Test sensitivity varied by race or ethnicity and tended to be lower for women than for men at equivalent cutoff points.

\section{Conclusions}

Some brief alcohol screening questionnaires have acceptable test properties for women, although test sensitivities vary by race or ethnicity and tend to be lower for women than for men. Using lower than usual thresholds for a positive screen may therefore be appropriate when giving alcohol screening questionnaires to women.

Ranges of sensitivities and specificities of alcohol screening questionnaires for women

\begin{tabular}{|c|c|c|c|}
\hline Test & Sensitivity, $\%$ & Specificity, \% & $\begin{array}{l}\text { Area under ROC } \\
\text { curve* }\end{array}$ \\
\hline CAGE $\geqslant 2$ (7 studies $)$ & 38 to 83 & 92 to 96 & \\
\hline CAGE $\geqslant 1$ ( 4 studies) & 59 to 89 & 81 to 86 & 0.76 to 0.92 \\
\hline AUDIT $\geqslant 8$ (3 studies) & 59 to 66 & 93 to 97 & \\
\hline AUDIT $\geqslant 7$ (1 study) & 70 & 95 & 0.87 \\
\hline $\begin{array}{l}\text { TWEAK (hold) } \geqslant 3 \text { (3 } \\
\text { studies) }\end{array}$ & 67 to 80 & 90 to 94 & \\
\hline $\begin{array}{l}\text { TWEAK (hold) } \geqslant 2 \text { (1 } \\
\text { study) }\end{array}$ & 87 & 87 & 0.90 \\
\hline BMAST $\geqslant 6$ (2 studies) & 23 to 53 & 97 to 99 & \\
\hline BMAST $\geqslant 4$ (1 study) & 57 & 90 & 0.75 \\
\hline $\begin{array}{l}\text { Trauma scale } \geqslant 2(3 \\
\text { studies) }\end{array}$ & 40 to 53 & 80 to 93 & 0.59 (1 study) \\
\hline T-ACE $\geqslant 1$ ( 2 studies $)$ & 76 to 91 & 70 to 79 & 0.84 to 0.89 ( 1 study) \\
\hline NET $\geqslant 1$ (1 study $)$ & 71 & 86 & 0.79 \\
\hline
\end{tabular}

$* \mathrm{ROC}=$ receiver operating characteristic.

Sources of funding: Health Services Research and Development Field Program and Medicine Service and VA Puget Sound Health Care System.

For correspondence: $\operatorname{Dr} K$ A Bradley, Health Services Research and Development, VA Puget Sound Health Care System (Seattle Division), 1660 S Columbian Way, Mail Stop 152, Seattle, WA 98108 , Health Care System (Seattle D
USA.Fax +12067642935.

Abstract and commentary also published in ACP Journal Club

\section{Commentary}

Dozens of studies confirm the efficacy of brief interventions for alcohol problems. Translating this evidence into practice has been difficult, however, because of limited physician time and expertise and under recognition of alcoholism. ${ }^{2}$ Although the CAGE questions are almost 25 years old, screening tools have only recently been tested in women, minorities, and the elderly, and used to detect hazardous drinkers (people drinking detrimental amounts but with no consequences). ${ }^{3}$

The systematic review by Bradley et al finds that alcohol screening questionnaires may be less sensitive for problem drinking in women than in men. The authors also point out that their conclusions should be viewed as tentative because, unfortunately, there were few studies to review.

Alcohol problems are more likely to be detected by standardised screening tools. ${ }^{2}$ For sex specific screening, the evidence supports using TWEAK (with questions about Tolerance, Worried, Eye openers, Amnesia, and Kut down) (2 points as a positive test) in women; it is brief, works in diverse populations, and detects current hazardous drinking (particularly important in women who are pregnant or con- sidering pregnancy). If one instrument is used for all patients, we need a brief, sensitive test that is valid in diverse populations and identifies both current and past hazardous and problem drinking.

Richard Saitz, MD, MPH Boston University School of Medicine Boston Medical Center Boston, Massachusetts, USA

1 Bien TH, Miller WR, Tonigan JS. Addiction 1993;88:315-35

1993;88:315-35.
Rydon P, Redman S, Sanson-Fisher RW, et al. .J Stud Alcohol 1992;53:197-202.

3 O'Connor PG, Schottenfeld RS. N Engl J Med 1998;338:592-602.

4 Kitchens JM. JAMA 1994;272:1782-7. 